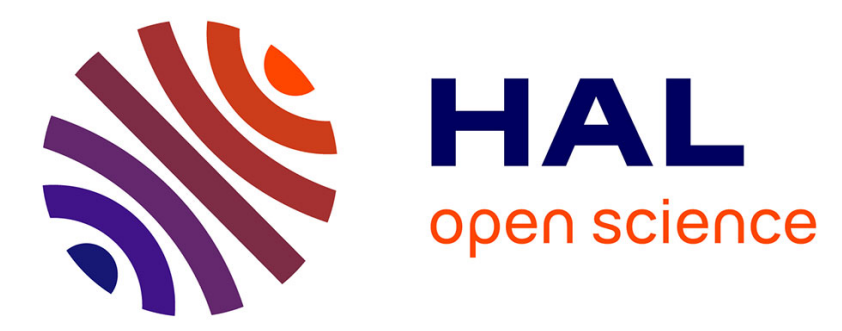

\title{
Effects of Ag-doped content on the microstructure and thermoelectric properties of CoSb 3 thin films
}

Ping Fan, Meng Wei, Zhuang-Hao Zheng, Xiang-Hua Zhang, Hong-Li Ma, Jing-Ting Luo, Guang-Xing Liang

\section{To cite this version:}

Ping Fan, Meng Wei, Zhuang-Hao Zheng, Xiang-Hua Zhang, Hong-Li Ma, et al.. Effects of Ag-doped content on the microstructure and thermoelectric properties of CoSb 3 thin films. Thin Solid Films, 2019, 679, pp.49-54. 10.1016/j.tsf.2019.04.008 . hal-02122166

HAL Id: hal-02122166

https://hal-univ-rennes1.archives-ouvertes.fr/hal-02122166

Submitted on 14 Jun 2019

HAL is a multi-disciplinary open access archive for the deposit and dissemination of scientific research documents, whether they are published or not. The documents may come from teaching and research institutions in France or abroad, or from public or private research centers.
L'archive ouverte pluridisciplinaire HAL, est destinée au dépôt et à la diffusion de documents scientifiques de niveau recherche, publiés ou non, émanant des établissements d'enseignement et de recherche français ou étrangers, des laboratoires publics ou privés. 


\section{Effects of Ag-doped content on the microstructure and thermoelectric properties of $\mathrm{CoSb}_{3}$ thin films}

Ping Fan ${ }^{\mathrm{a},} *$, Meng Wei ${ }^{\mathrm{a}}$, Zhuang-hao Zheng ${ }^{\mathrm{a}}$, Xiang-hua Zhang ${ }^{\mathrm{b}}$, Hong-li Ma ${ }^{\mathrm{b}}$, Jing-ting Luo ${ }^{\text {a }}$, Guang-xing Liang ${ }^{\text {a }}$

a Institute of Thin Film Physics and Applications, Shenzhen Key Laboratory of Advanced Thin Films and Applications, College of Physics and Energy, Shenzhen University 518060, China

b Laboratory of Glasses and Ceramics, Institute of Chemical Science UMR CNRS 6226, University of Rennes 1, Rennes 35042, France.

* Corresponding author. E-mail: fanping308@126.com

Abstract: In this work, $\mathrm{Ag}$ doped $\mathrm{CoSb}_{3}$ thin films were grown directly on the heated substrate by the simple and effective magnetron sputtering process. The micro-structure and thermoelectric properties of the doped thin films are found to strongly depend on the Ag doping content. High-resolution transmission electron microscope image and corresponding selected-area electron diffraction pattern confirm that the doped thin film has single $\mathrm{CoSb}_{3}$ crystal structure with well-crystallized. The high crystal quality of the doped thin film will lead to good thermoelectric properties. As expected, both the electrical conductivity and Seebeck coefficient are greatly enhanced after Ag doping, resulting in the enhancement of power factor, suggesting that the proposed strategy can be applied to prepare high-performance thermoelectric thin films.

Keywords: Thermoelectricity; Thin films; Cobalt antimonide; Silver; Doping. 


\section{Introduction}

Thermoelectric (TE) device can directly convert heat emanating from the Sun, radioisotopes, automobiles, industrial sectors, or even the human body to electricity [1]. Meanwhile, electricity also can drive a TE device to work as a solid-state heat pump [2]. Therefore, it has gained great interest for their potential applications in many fields, including direct conversion of waste heat from industrial sectors or automobile exhausts to electricity, and solid-state Peltier coolers. Performance of the TE device is related to the dimensionless figure of merit ZT values, which is determined by the Seebeck coefficient $(S)$, electrical conductivity $(\sigma)$, and thermal conductivity ( $\kappa$ ), expressed using an equation of $\mathrm{ZT}=S^{2} \sigma T / \kappa$, where $T$ is the working temperature, $S^{2} \sigma$ is defined as the power factor (PF), and $\kappa$ includes the electronic thermal conductivity $\kappa_{\text {ele }}$ and the lattice thermal conductivity $\kappa_{\text {lat }}\left(\kappa=\kappa_{\text {ele }}+\kappa_{\text {lat }}\right)$ [3].

Recently, increasing demand in micro-scale energy harvesting for power supplies and miniaturized sensors has prompted the investigation of multifunctional micro-TE devices [4]. But traditional TE device manufacturing technique can not meet the requirements of the miniaturization device, such as the micro-size, light weight and high energy density, especially flexible and wearable [5]. Therefore, the demand to apply micro-TE device as an alternative power source for small electric devices and systems are constantly increasing and the research in the micro-TE device are more and more attracting interesting.

Thus, various studied in the preparation of micro-TE device has been done [5-10]. Among them, micro-TE device fabricated based on thin film technique are one of the 
most widely studied research fields [11-15]. The reason for this is not only because of the thin films with nanostructure can control the phonon transport by the quantum confinement effect, leading to enhance the TE performance of the materials [16-17], but also due to thin film device offers many advantages, including flexibility, small volume, light weight, high integration, and enhanced compatibility. Moreover, thin film preparing technology is already compatible in the semiconductor manufactory industry. Therefore, thin film TE devices have been considered as the promising technology for realizing the practical of micro-TE application. Consequently, there is a significant demand to develop high-performance thin film TE materials and devices.

Skutterudite $\mathrm{CoSb}_{3}$ and its related compounds have drawn extensive attention as one of the most promising thermoelectric materials in the intermediate temperature range over the past few decades [18-24]. It is a narrow band gap semiconductor, owning larger carrier mobility, high Seebeck coefficient and complex crystal structure. Especially, $\mathrm{CoSb}_{3}$ crystallizes in a body-centered cubic structure with space group Im3 and a unit cell consists of 32 atoms, in which Co atoms form eight sub-cubes with pnicogen rings occupying six of them, leaving the final two voids or cages empty. Thus, if the doped-element can fill into these voids, the Seebeck coefficient would be enhanced and the thermal conductivity reduced, resulting in dramatically increase of ZT value due to the "rattling" effect of filling which can effectively scatter wider-range amplified phonons [25-30]. For instance, Wang et al. demonstrated that the introduction of $\mathrm{Yb}$ in $\mathrm{CoSb}_{3}$ can raise the $\mathrm{ZT}$ value from 0.5 to 1.5 at $850 \mathrm{~K}$ and a high average value of $\sim 1.27$ within $500 \mathrm{~K}-850 \mathrm{~K}$ was obtained with the optimized 
Yb content of $0.29 \%$ [27]. Shi et al. reported that the multi-filling of $\mathrm{CoSb}_{3}$ can lead to a maximum ZT of 1.7 at $850 \mathrm{~K}$, which is several times higher than the pure sample [28]. G. Rogl et al. demonstrated that In-doped multi-filled n-type skutterudites can exhibit a high power factor and a very low thermal conductivity, leading to an outstanding ZT value of 1.8 at $823 \mathrm{~K}$ [29]. Zhou et al. shown that the ZT is $30 \%$ higher in comparison to the $\mathrm{Ba}$ filled $\mathrm{CoSb}_{3}$ after inclusion of $\mathrm{Ag}$ nanoparticle [30]. Although filling is an efficient way for improving the properties of $\mathrm{CoSb}_{3}$ materials, reports on the thermoelectric properties of filled-CoSb 3 thin films were scarce.

In our previous work, we found that the Ag can fill into the lattice voids and efficiently regulate the performance of the $\mathrm{CoSb}_{3}$ thin film. However, there are many defect states on the thin film surface impeding the further improvement of thin film thermoelectric properties [31]. Recently, we have found that the $\mathrm{CoSb}_{3}$ thin film had less surface defects when heated the substrate during the thin film deposition, rather than annealing after deposition process [32]. Therefore, in this work, Ag doped thin films were grown directly on the heated substrate with fixed temperature, and the microstructure and thermoelectric properties of the thin films were investigated. As expected, the thin film with great crystallinity and enhanced thermoelectric properties were obtained.

\section{Experimental details}

Ag target (99.99\%) and $\mathrm{CoSb}_{3}(99.95 \%)$ alloy target with $\mathrm{Co} / \mathrm{Sb}$ atomic ratio of 1:3 were fixed in the magnetron sputtering facility, equipped with a three-position rotatable target system. The sputtering angle was $45^{\circ}$ and the target-substrate distance 
was $10 \mathrm{~cm}$. Glass substrates were used and cleaned in a ultrasonic bath for 10 minutes in acetone, $10 \mathrm{~min}$ in absolute ethyl alcohol and $10 \mathrm{~min}$ in deionized water. The vacuum chamber was firstly pumped down to $8.0 \times 10^{-4} \mathrm{~Pa}$ and the working pressure was kept at $0.4 \mathrm{~Pa}$ with argon flow of $40 \mathrm{sccm}$. As shown in Figure 1, the glass substrate was heated to be $250{ }^{\circ} \mathrm{C}$ before the deposition process. Then the $\mathrm{CoSb}_{3}$ layer was deposited onto the substrate with a sputtering power of $50 \mathrm{~W}$ and the deposition time is $15 \mathrm{~min}$. During the middle of the $\mathrm{CoSb}_{3}$ layer deposition process, the $\mathrm{Ag}$ was co-deposited by using a sputtering power of $1 \mathrm{~W}$. For this co-sputtering layer, the deposition time was adjusted from $10 \mathrm{~s}$ to $60 \mathrm{~s}$ with interval of $10 \mathrm{~s}$ for controlling the Ag content. The content of Ag was analyzed by energy dispersive spectroscopy and was respectively $0.3 \%, 1.6 \%, 2.2 \%, 3.8 \%, 4.6 \%$ and $5.1 \%$ for different co-deposition time. Some details of the thin films were shown in Table 1.

The crystalline phases were determined by X-ray diffraction (XRD) (D/max2500, Rigaku Corporation) with the $2 \theta$ angle range of $10^{\circ}-80^{\circ}$, using $\mathrm{Cu} \mathrm{K}_{\alpha}$ radiation $(\lambda=$ $0.15406 \mathrm{~nm}$ ). Raman scattering measurements were performed by using a spectra system Lab Ram Xplora (Horiba Jobin Yvon). The laser excitation was the $514.5 \mathrm{~nm}$ line of an $\mathrm{Ar}^{+}$ion laser. The micro-structure was characterized by using scanning electron microscopy (SEM, Zeiss supra 55) and transmission electron microscopy (TEM, JEM-3200FS) with the operating voltage of $3 \mathrm{KV}$ and $300 \mathrm{KV}$, while the composition analysis was performed by energy dispersive spectroscopy (EDS). The TEM sample was prepared by following process: thin film was firstly scratched down from the substrate and put into the alcohol. Then, the solution was dripped onto the 
copper mesh after stirred for ten minutes. The electrical conductivity and Seebeck coefficient were simultaneously measured in the interval of $298 \mathrm{~K} \sim 573 \mathrm{~K}$ by using a Nezsch- SBA458 equipment.

\section{Results and discussion}

The crystalline phases were determined by X-ray diffraction (XRD) with the $2 \theta$ angle range of $10^{\circ}-80^{\circ}$, using $\mathrm{Cu} \mathrm{K} \alpha$ radiation $(\lambda=0.15406 \mathrm{~nm})$. Figure 2 shows the $\mathrm{XRD}$ patterns of $\mathrm{Ag}$ doped $\mathrm{CoSb}_{3}$ thin films, including the un-doped sample. After comparison to the characteristic $\mathrm{CoSb}_{3}$ pattern, three main diffraction peaks located at $\sim 32^{\circ}, \sim 37^{\circ}$, and $\sim 46^{\circ}$ from $\mathrm{Ag}$-doped $\mathrm{CoSb}_{3}$ thin films are defined as the $\mathrm{CoSb}_{3}$ (013) (123) and (420) planes. There are many weak peaks in all the patterns and they also can be attributed to the $\mathrm{CoSb}_{3}$ skutterudite structure, indicating that all the thin films are composed of pure $\mathrm{CoSb}_{3}$ structure. As shown in the inset of Figure 2, the peak slightly shifts to smaller angle after Ag doping and the shift increases with increasing Ag content, suggesting crystal cell expansion. To further confirm the Ag state in the films. Raman scattering measurements were used and the results are shown in Figure 3. Four modes are observed in the patterns of all the samples at the positions around $\sim 106 \mathrm{~cm}^{-1}, \sim 131 \mathrm{~cm}^{-1}, \sim 146 \mathrm{~cm}^{-1}$ and $\sim 179 \mathrm{~cm}^{-1}$, corresponding respectively to the $\mathrm{F}_{\mathrm{g} 2}, \mathrm{E}_{\mathrm{g} 1}, \mathrm{~A}_{\mathrm{g} 1}$ and $\mathrm{A}_{\mathrm{g} 2}$ Raman sensitive phonon vibration modes in $\mathrm{CoSb}_{3}$ predicted by theoretical simulation (The positions of $\mathrm{CoSb}_{3}$ theoretical standard Raman peaks are around $\sim 83 \mathrm{~cm}^{-1}, \sim 97 \mathrm{~cm}^{-1}, \sim 139 \mathrm{~cm}^{-1}, \sim 150 \mathrm{~cm}^{-1}, \sim 157$ $\mathrm{cm}^{-1}, \sim 178 \mathrm{~cm}^{-1}$ and $\sim 179 \mathrm{~cm}^{-1}, \sim 182 \mathrm{~cm}^{-1}$, corresponding respectively to the $\mathrm{Fg} 1, \mathrm{Fg}$, Eg1, Ag1, Fg3, Fg4, Ag2 and Eg2 Raman sensitive phonon vibration modes) [33]. No 
extra peak can be observed, confirming that the films have single cubic structure. Additionally, the disorder Raman peak shifts are due to the lattice expansion. Comparing to our previous work [31], similar results can be found, suggesting that the $\mathrm{Ag}$ is most likely filling into the vacant lattice void.

Figure 4 shows surface morphology of thin films, observed using SEM. The results reveal that all the samples exhibit a smooth and dense surface across the entire surface with uniform particles forming more or less large grains. The morphology of the films do not have obvious change after Ag doping. These findings indicate that all the thin films have no obvious crystal imperfection, which should be favorable for electronic transport. The elemental mappings of the sample with Ag content of $3.8 \%$ are shown in Figure 5(a) and the results indicate that all the elements are homogenously distributed in the thin films. High-resolution (HR) TEM image and corresponding selected-area electron diffraction (SAED) pattern are shown in Figure 5(b). It indicates that the film has single crystal structure and the interplanar d-spacings of $0.294 \mathrm{~nm}$ and $0.255 \mathrm{~nm}$ correspond respectively to the (013) and (123) planes of the skutterudite $\mathrm{CoSb}_{3}$. The $\mathrm{SAED}$ result further confirms the $\mathrm{CoSb}_{3}$ crystalline phase. The different shades of the grey caused by the different thickness of the position. Therefore, the SEM and HRTEM results indicate that the thin film has high crystal quality with few grain boundaries or other interfaces for electrons scattering, which should lead to good electronic transport property.

Figure 6(a) shows the electrical conductivity, $\sigma$, as function of temperature. It can be found that the electrical conductivities of un-doped sample is $0.16 \times 10^{4} \mathrm{~S} \cdot \mathrm{m}^{-1}$ at 
room-temperature, and is enhanced after Ag doping. Comparatively, samples which Ag contents are $>4.6 \%$ yield high electrical conductivity over $0.26 \times 10^{4} \mathrm{~S} \cdot \mathrm{m}^{-1}$. The carrier concentration $n$ of the samples with Ag content of $4.6 \%$ and $5.1 \%$ has been measured at room temperature, together with the un-doped sample. The carrier concentration was shown in Table 1 . The $\sigma$ of all the samples increases with the increasing temperature which shows their thermal stability due to the dense structure with good crystallinity. The $\sigma$ of Ag-doped samples have similar value over $0.50 \times 10^{4}$ $\mathrm{S} \cdot \mathrm{m}^{-1}$ and the film with Ag content of $2.2 \%$ has the highest value of $0.65 \times 10^{4} \mathrm{~S} \cdot \mathrm{m}^{-1}$ at $623 \mathrm{~K}$ among these samples.

Figure 6(b) illustrates the temperature dependence of the Seebeck coefficient, $S$, of the thin films. As shown in Figure 6(b), the Seebeck coefficient of all the samples is negative, exhibiting n-type conduction. $S$ of un-doped sample yields a value of -24.1 $\mu \mathrm{V} \cdot \mathrm{K}^{-1}$ at $298 \mathrm{~K}$ which is an extremely low value compared to that of the $\mathrm{CoSb}_{3}$ bulk materials, which is about $220 \mu \mathrm{V} \cdot \mathrm{K}^{-1}$ [29]. The absolute $S$ value is obviously enhanced when the Ag doping content is $\leq 2.2 \%$, especially for the sample with $\mathrm{Ag}$ content of $0.3 \%$. It has the absolute $S$ value of $43.3 \mu \mathrm{V} \cdot \mathrm{K}^{-1}$ which is two times of the un-doped thin film. But the $S$ value of $\mathrm{Ag}$ doped thin films is close to the value of the un-doped sample when the films have high Ag doping content of $>3.8 \%$. The absolute $S$ values of all the samples increases with increasing temperature and the $S$ of samples with low Ag doping content sharply increases in their absolute value with increasing temperature, which reach to $241.8 \mu \mathrm{V} \cdot \mathrm{K}^{-1}$ and $174.9 \mu \mathrm{V} \cdot \mathrm{K}^{-1}$ at $623 \mathrm{~K}$ when the $\mathrm{Ag}$ content is $0.3 \%$ and $1.6 \%$, respectively. But samples will have close and lower $S$ 
values at high measuring temperatures with increasing $\mathrm{Ag}$ doping content.

From figures 6(a) and (b), it is worth noting that both of the Seebeck coefficient and the electrical conductivity are enhanced by appropriate Ag doping content. Generally, the $S$ and $\sigma$ are both dependent on the carrier concentration with inverse relationship. Thus, it demonstrates that $\mathrm{Ag}$ is an efficient dopant that can resolve the conflict between $S$ and $\sigma$ which might attribute to the increased carrier concentration and electron effective mass after the Ag-doping [31]. Additionally, the room-temperature Seebeck coefficient and electrical conductivity of the thin films were measured for three times and the results show that their have few change, indicating high thermal stability of the films.

The temperature dependence of $\mathrm{PF}$ at the temperature range from $298 \mathrm{~K}$ to $623 \mathrm{~K}$ is shown in Figure 6(c) and the inset shows the PF value between $298 \mathrm{~K}$ to $498 \mathrm{~K}$. The PF value shows increasing trend as function of temperature for all the samples and the PF value of the Ag-doped samples is higher than the un-doped sample when the temperature is under $498 \mathrm{~K}$ as shown in the inset. Although some films have slightly lower value than that of the un-doped sample at higher temperature, the Ag-doped samples generally have larger PF value on the whole. The maximum PF value of $2.97 \times 10^{-4} \mathrm{Wm}^{-1} \mathrm{~K}^{-2}$ is obtained from the film with $\mathrm{Ag}$ content of $0.3 \%$, which is two times of the un-doped sample's PF value.

\section{Conclusion}

The micro-structure and thermoelectric properties of $\mathrm{Ag}$ doped $\mathrm{CoSb}_{3}$ thin films which grew directly on the heated substrate with various $\mathrm{Ag}$ contents were 
investigated. The microstructure analysis confirms that the doped thin films have well-crystallized, and the Ag have entered into the lattice and most likely occupy the lattice voids. Due to the improved crystallinity and Ag filling effect, the Seebeck coefficient and electrical conductivity are significantly enhanced. As expected, the power factor is increased to a high value of $2.97 \times 10^{-4} \mathrm{Wm}^{-1} \mathrm{~K}^{-2}$ which is almost $100 \%$ enhancement after Ag doping.

\section{Acknowledgement}

This work is supported by National Natural Science Foundation of China (No. 11604212), Key platform and research projects, Education and Research of Guangdong Province (2015KQNCX139), and Shenzhen Key Lab Fund (ZDSYS 20170228105421966).

\section{Reference}

[1]. J. He, T.M. Tritt, Advances in thermoelectric materials research: Looking back and moving forward, Science, 2017, 357: 1369.

[2]. J.D. Francis, Thermoelectric Cooling and Power Generation, Science, 1999, 285: 703-706

[3]. G.J. Snyde, E.S. Toberer, Complex thermoelectric materials, Nat. Mater., 2008, 7: 105-114.

[4]. J.P. Rojas, D. Singh, S.B. Inayat, G.A.T. Sevilla, H.M. Fahad, M.M. Hussain, Review-micro and nano-engineering enabled new generation of thermoelectric generator devices and applications, ECS J. Solid State Sci. Technol., 2017, 6: 3036-3044. 
[5]. L.E. Bell, Cooling, Heating, Generating Power, and Recovering Waste Heat with Thermoelectric Systems, Science, 2008, 321: 1457-1461.

[6]. W. He, G. Zhang, X. Zhang, J. Ji, G. Li, X. Zhao, Recent development and application of thermoelectric generator and cooler, Appl. Energ., 2015, 143:1-25.

[7]. M.K. Kim, M.S. Kim, S. Lee, C. Kim, Y.J. Kim, Wearable thermoelectric generator for harvesting human body heat energy, Smart Mater. Struct., 2014, 23: 105002.

[8]. Z. Lu, H. Zhang, C. Mao, C.M. Li, Silk fabric-based wearable thermoelectric generator for energy harvesting from the human body, Appl. Energ., 2016, 164:57-63.

[9]. Z.H. Zheng, J.T. Luo, T.B. Chen, X.H. Zhang, G.X. Liang, P. Fan, Using high thermal stability flexible thin film thermoelectric generator at moderate temperature, Appl. Phys. Lett., 2018, 112: 163901.

[10]. Y. Chen, Y. Zhao, Z. Liang, Solution processed organic thermoelectrics: towards flexible thermoelectric modules, Energy Environ. Sci., 2015,8: 401-422.

[11]. R. Venkatasubramanian, E. Siivola, T. Colpitts, B. O'Quinn, Thin- film thermoelectric devices with high room-temperature figures of merit, Nature, 2001, 413: 597-602.

[12]. G. Bulman, P. Barletta, J. Lewis, N. Baldasaro, M. Manno, A.B. Cohen, B. Yang, Superlattice based thin film thermoelectric modules with high cooling fluxes, Nat. Commun., 2016, 7: 10302. 
[13]. C. Chen, D. Madan, P.K. Wright, J.W. Evans, Dispenser-printed planar thick-film thermoelectric energy generators, J. Micromech. Microeng., 2011, 21 : 104006.

[14]. N.W. Park, T.H. Park, J.Y. Ahn, S.H. Kang, W.Y. Lee, Y.G. Yoon, S.G. Yoon, S.K. Lee, Thermoelectric characterization and fabrication of nanostructured p-type $\mathrm{Bi}_{0.5} \mathrm{Sb}_{1.5} \mathrm{Te}_{3}$ and $\mathrm{n}$-type $\mathrm{Bi}_{2} \mathrm{Te}_{3}$ thin film thermoelectric energy generator with an in-plane planar structure, AIP Adv., 2016, 6: 065123.

[15]. P. Fan, Z.H. Zheng, Y.Z. Li, Q.Y. Lin, J.T. Luo, G.X. Liang, X.M. Cai, D.P. Zhang, F. Ye, Low-cost flexible thin film thermoelectric generator on zinc based thermoelectric materials, Appl, Phys, Lett., 2015, 106: 073901.

[16]. D.F. Ding, D.W. Wang, M. Zhao, J.W. Lv, H. Jiang, C.G. Lu, Z.Y. Tang, Interface engineering in solution-processed nanocrystal thin films for improved thermoelectric performance, Adv. Mater., 2016, 29: 1603444.

[17]. L.D. Hicks, M.S. Dresslhaus, Thermoelectric figure of merit of a one-dimensional conductor, Phys. Rev. B, 1993, 47: 16631.

[18]. J.O. Sofo, G.D. Mahan, Electronic structure of $\mathrm{CoSb}_{3}$ : A narrow-band-gap semic onductor, Phys. Rev. B, 1998, 58: 15620.

[19]. M. Christensen, A.B. Abrahamsen, N.B. Christensen, F. Juranyi, N.H. Andersen, K. Lefmann, J. Andreasson, C.R.H. Bahl, B.B. Iversen, Avoided crossing of rattler modes in thermoelectric materials, Nat. Mater., 2008, 7: 811-815. 
[20]. J.L. Feldman, D.J. Singh, Lattice dynamics of skutterudites: First-principles and model calculations for $\mathrm{CoSb}_{3}$, Phys. Rev. B, 1996, 53: 6273.

[21]. B. Feng, J. Xie, G. Cao, T. Zhu, X. Zhao, Enhanced thermoelectric properties of p-type $\mathrm{CoSb}_{3}$ /graphene nanocomposite, J. Mater. Chem. A, 2013, 42: 13111-13119.

[22]. M.D. Hornbostel, E.J. Hyer, J. Thiel, D.C. Johnson, Rational Synthesis of Metastable Skutterudite Compounds Using Multilayer Precursors, J. Am. Chem. Soc., 1997, 119: 2665-2668.

[23]. X. Shi, W. Zhang, L.D. Chen, J. Yang, Filling Fraction Limit for Intrinsic Voids in Crystals: Doping in Skutterudites, Phys. Rev. Lett., 2005, 95: 185503.

[24]. B.R. Ortiz, C.M. Crawford, R.W. McKinney, P.A. Parillab, E.S. Toberer, Thermoelectric properties of bromine filled $\mathrm{CoSb}_{3}$ skutterudite, J. Mater. Chem. A, 2016, 4: 8444-8450.

[25]. C. Chen, L. Zhang, J.H. Li, F.R. Yu, D.L. Yu, Y.J. Tian, B. Xu, Enhanced thermoelectric performance of lanthanum filled $\mathrm{CoSb}_{3}$ synthesized under high pressure, J. Alloys Compd., 2017, 699: 751-755.

[26]. M. Puyet, B. Lenoir, A. Dauscher, M. Dehmas, C. Stiewe, E. Müller, High temperature transport properties of partially filled $\mathrm{Ca}_{\mathrm{x}} \mathrm{Co}_{4} \mathrm{Sb}_{12}$ skutterudites, J. Appl. Phys., 2004, 95: 4852.

[27]. S. Wang, J.R. Salvador, J. Yang, P. Wei, B. Duan, J.H. Yang, High-performance n-type $\mathrm{Yb}_{\mathrm{x}} \mathrm{Co}_{4} \mathrm{Sb}_{12}$ : from partially filled skutterudites towards composite thermoelectrics, NPG Asia Mater., 2016, 8: 285. 
[28]. X. Shi, J. Yang, J.R. Salvador, M.F. Chi, J.Y. Cho, H.Wan, S. Bai, J. Yang, W. Zhang, L. Chen, Multiple-Filled skutterudites: high thermoelectric figure of merit through separately optimizing electrical and thermal transports, J. Am. Chem. Soc., 2011, 133: 7837-7846.

[29]. G. Rogl, A. Grytsiv, K. Yubut, S. Puchegger, E. Bauer, C. Raju, R.C. Mallik, P.Rogl, In-doped multifilled n-type skutterudites with $\mathrm{ZT}=1.8$, Acta Mater., 2015, 95: 201-211.

[30]. X.Y. Zhou, G.Y. Wang, L. Zhang, H. Chi, X.L. Su, J. Sakamoto, C. Uher, Enhanced thermoelectric properties of Ba-filled skutterudites by grain size reduction and $\mathrm{Ag}$ nanoparticle inclusion, J. Mater. Chem., 2012, 22: 2958-2964.

[31]. Z.H. Zheng, M. Wei, J.T. Luo, F. Li, G.X. Liang, Y. Liang, J. Hao, H.L. Ma, X.H. Zhang, P. Fan, Enhanced power factor via multilayer growth of Ag-doped skutterudite $\mathrm{CoSb}_{3}$ thin films, Inorg. Chem. Front., 2018, 5: 1409-1414.

[32]. Z.H. Zheng, M. Wei, F. Li, J.T. Luo, G.X. Liang, H.L. Ma, X.H. Zhang, P. Fan, Improvement of power factor of $\mathrm{CoSb}_{3}$ thermoelectric thin films via microstructure optimization, Coatings, 2017, 7: 205.

[33] J. L. Feldman, D. J. Singh. Lattice dynamics of skutterudites: First-principles and model calculations for $\mathrm{CoSb}_{3}[\mathrm{~J}]$. Phys Rev B, 1996, 53: 6273. 
Table 1 Thickness and carrier concentration of the thin films as function of Ag content

\begin{tabular}{|c|c|c|c|c|c|c|c|}
\hline $\begin{array}{c}\text { Ag-doped contents } \\
\text { (at.\%) }\end{array}$ & 0 & 0.3 & 1.6 & 2.2 & 3.8 & 4.6 & 5.1 \\
\hline $\begin{array}{l}\text { Thickness of film } \\
\text { (nm) }\end{array}$ & 170 & 177 & 175 & 180 & 180 & 185 & 187 \\
\hline $\begin{array}{l}\text { Carrier concentration } \\
\qquad\left(\times 10^{21} / \mathrm{cm}^{3}\right)\end{array}$ & 0.17 & 1.33 & 1.55 & 1.67 & 1.77 & 1.98 & 2.55 \\
\hline
\end{tabular}

\section{Figure Captions}

Figure 1 Preparing detail of the $\mathrm{Ag}$ doped $\mathrm{CoSb}_{3}$ thin films.

Figure $2 \mathrm{XRD}$ patterns of the samples.

Figure 3 The results of Raman spectrum for $\mathrm{CoSb}_{3}$ doped with different $\mathrm{Ag}$ content.

Figure 4 SEM surface morphology of Ag-doped $\mathrm{CoSb}_{3}$ thin films.

Figure 5 (a) The TEM image and elemental mappings, (b) HRTEM image of the Ag-doped sample.

Figure 6 Temperature dependence of (a) Electrical conductivity, (b) Seebeck coefficient, (c) Power factor PF. 


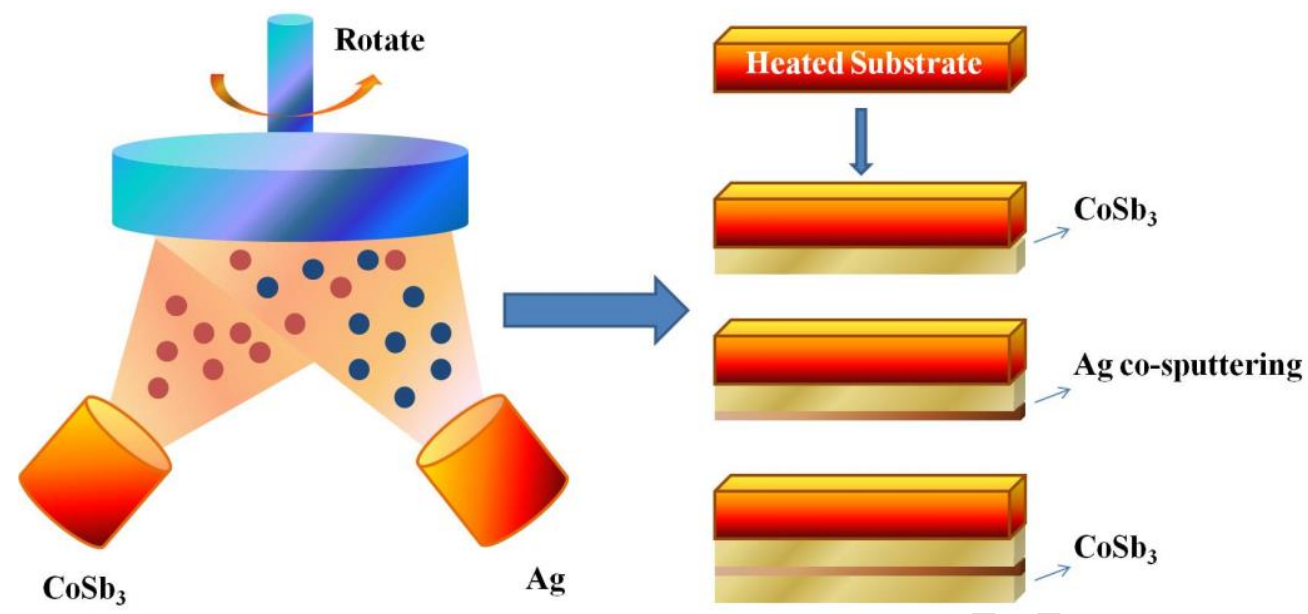

Figure 1

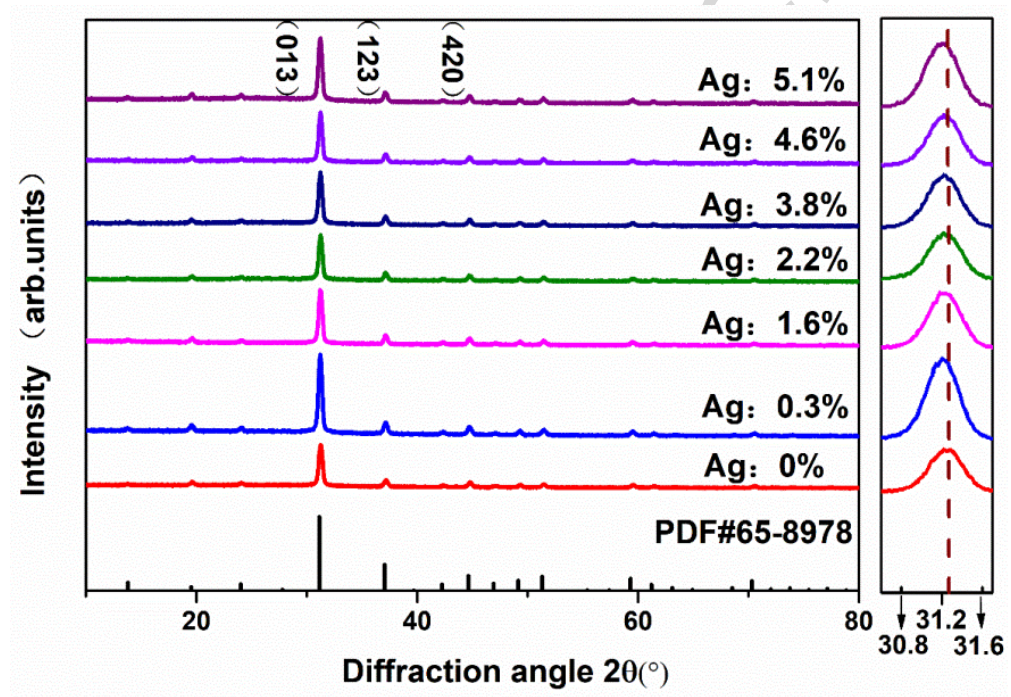

Figure 2

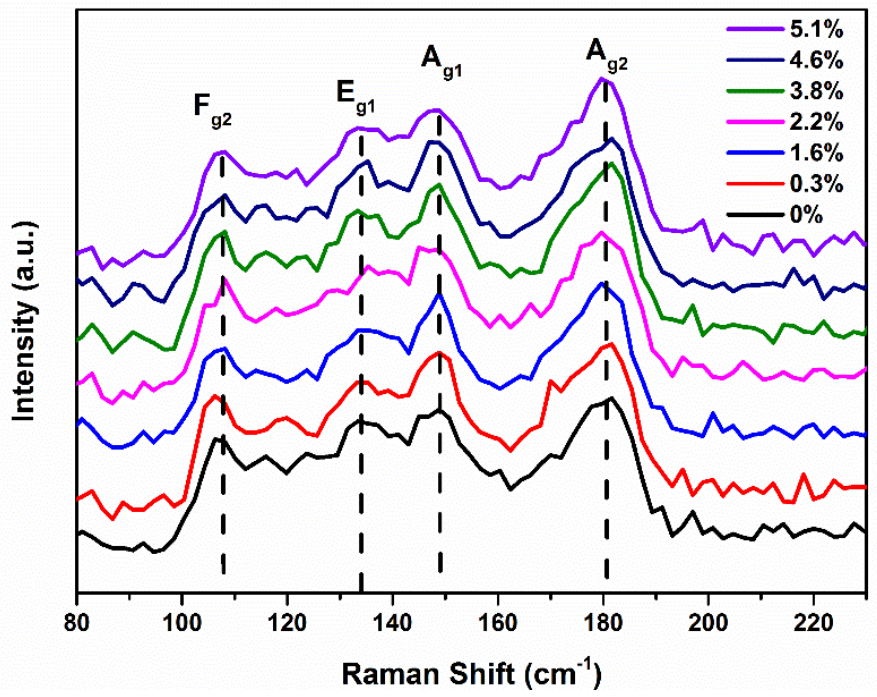

Figure 3 

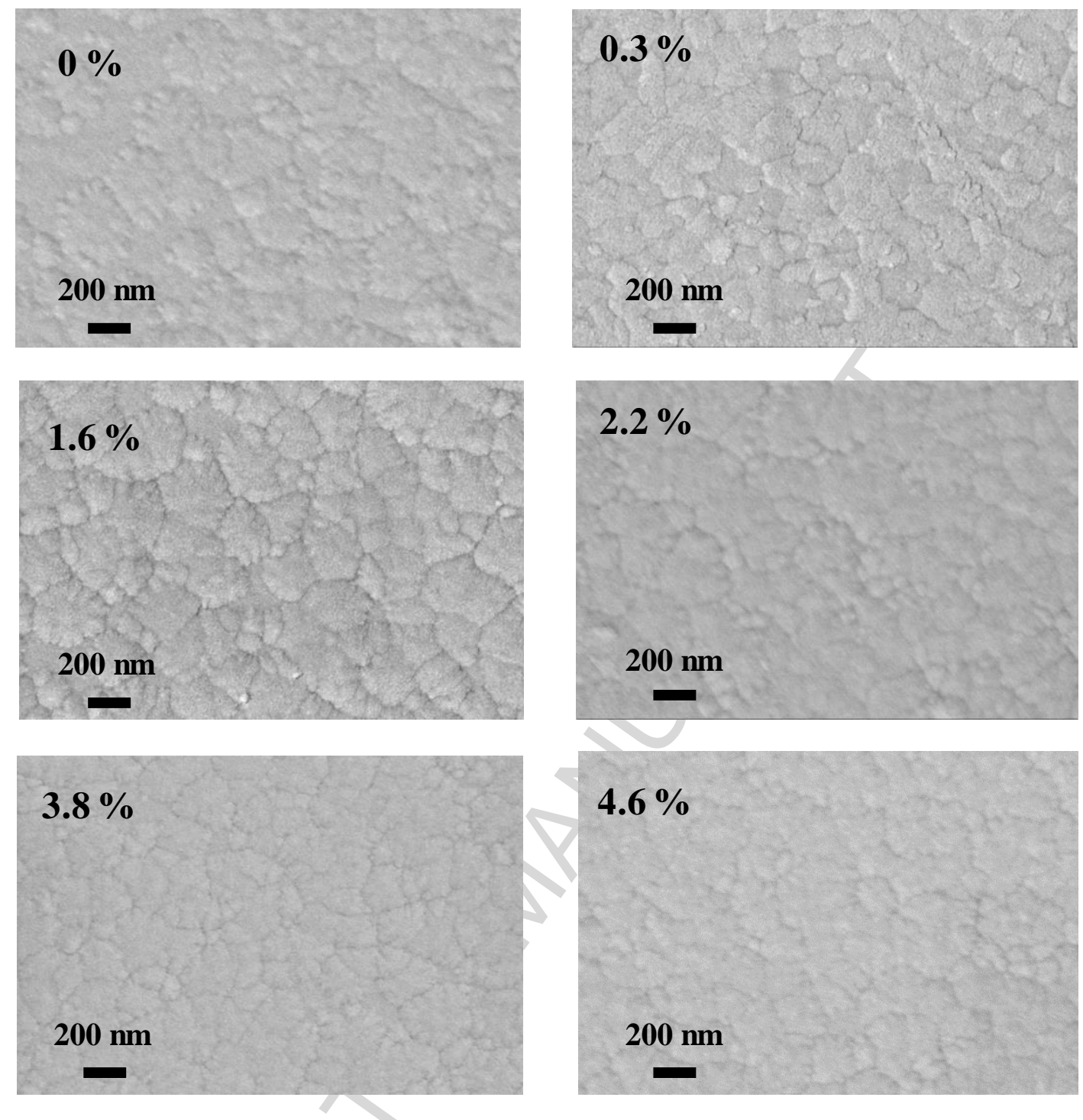

\section{$4.6 \%$}

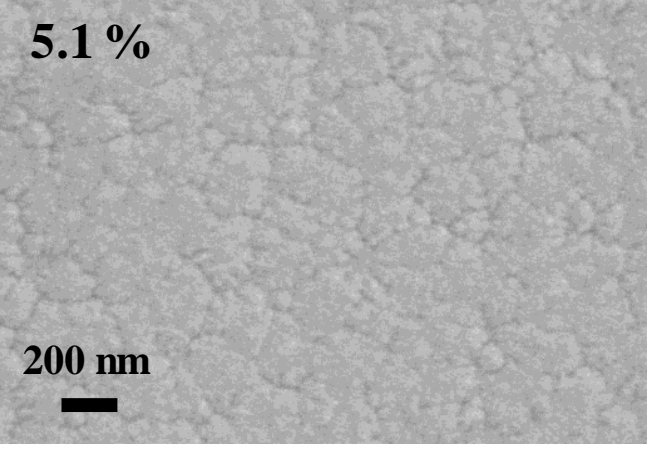

Figure 4 
(a)
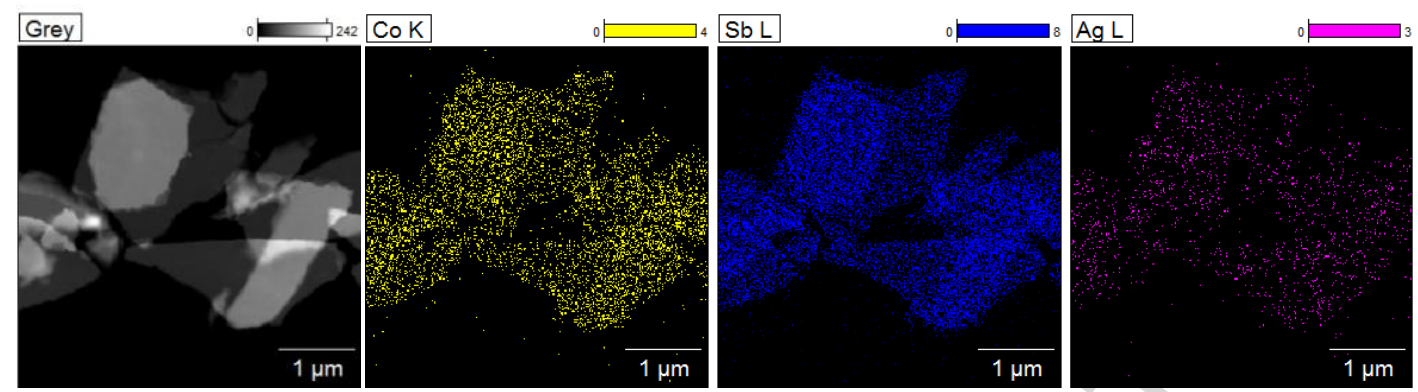

(b)
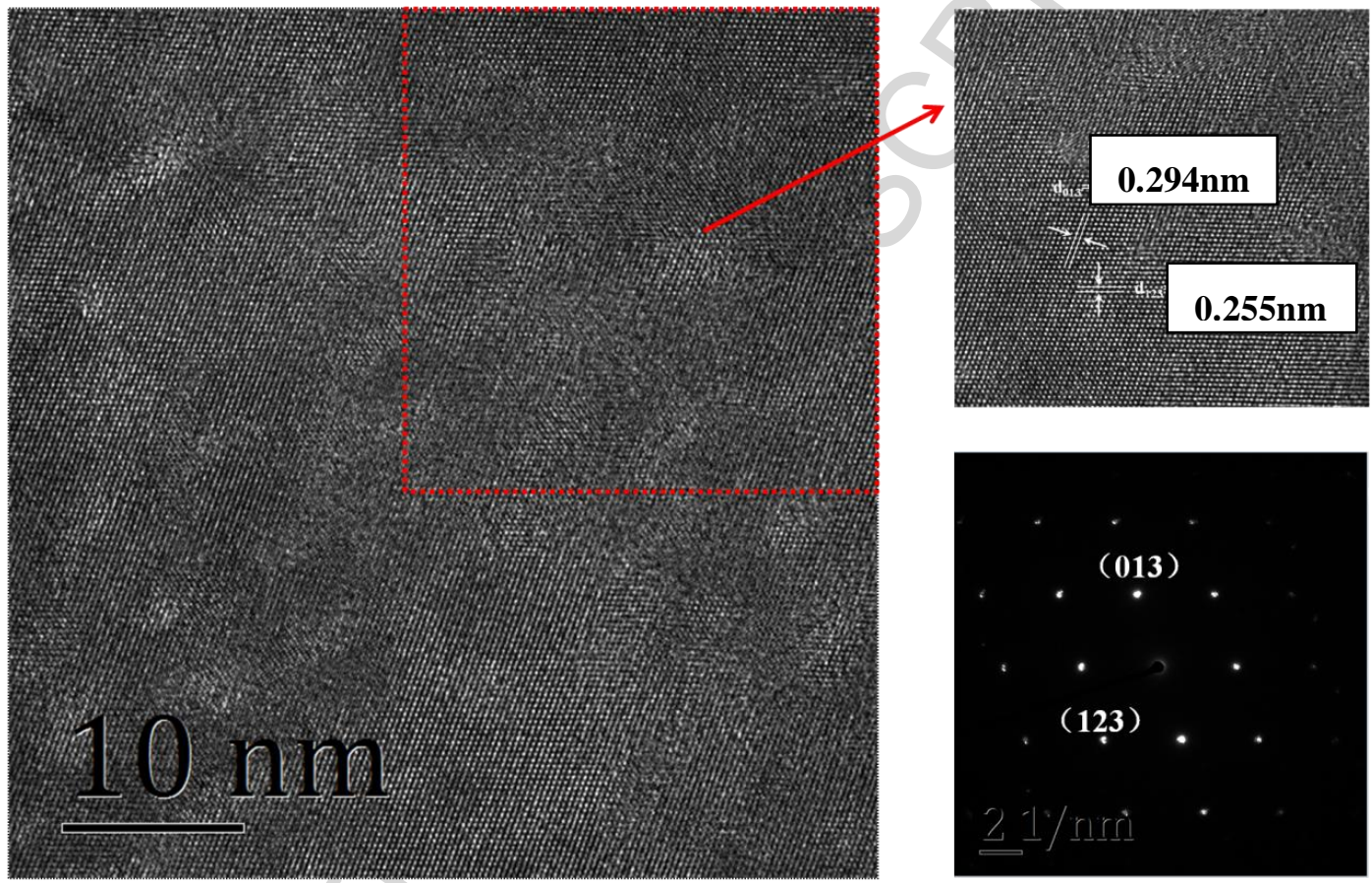

Figure 5 

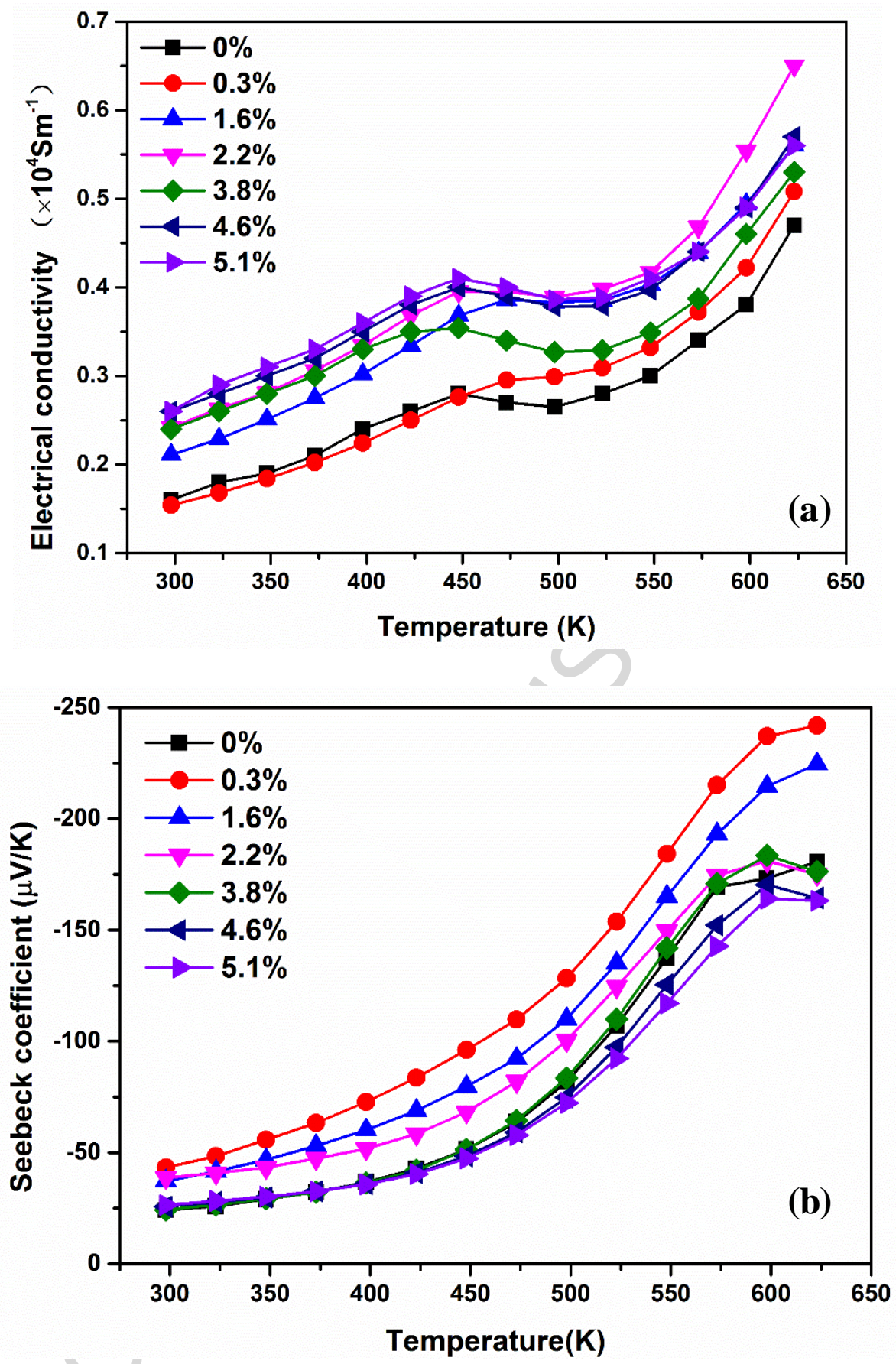


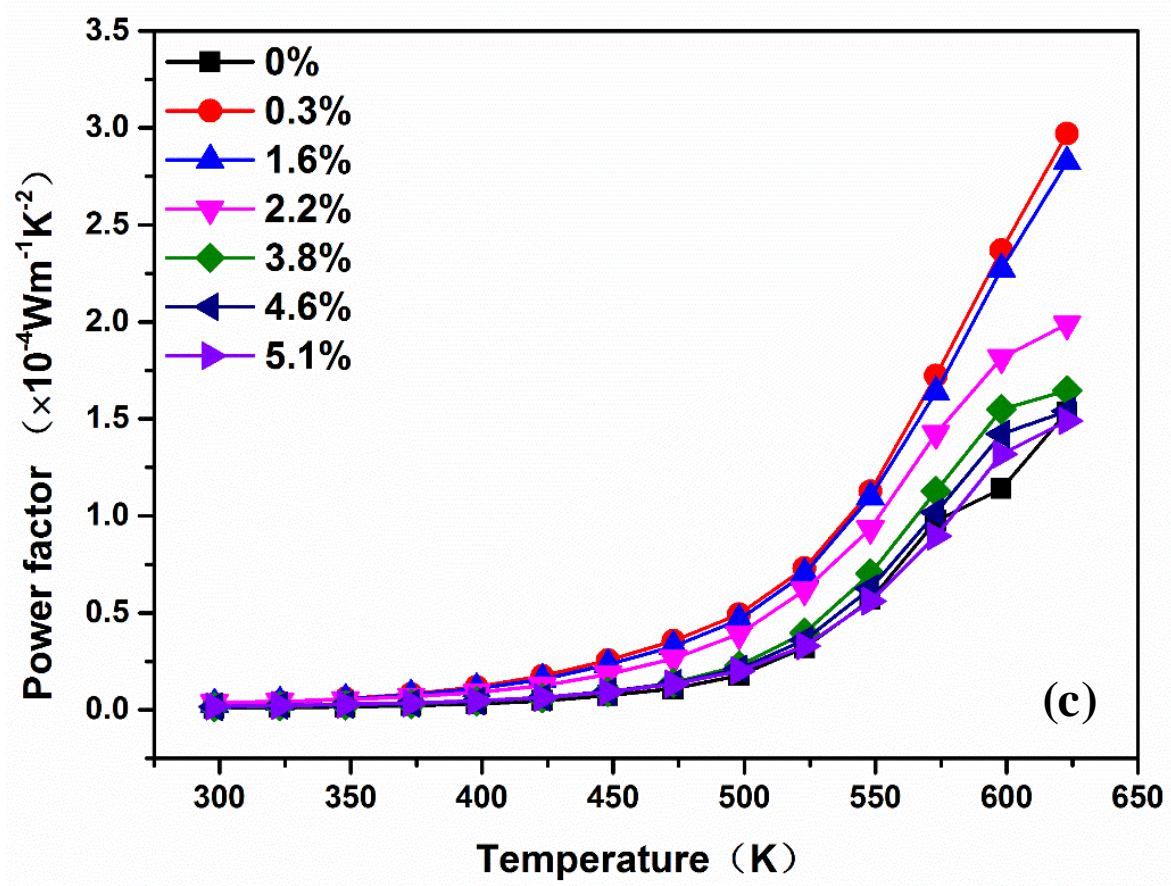

Figure 6 


\section{Highlights}

1. Ag doped $\mathrm{CoSb}_{3}$ films were grown directly on the heated substrate.

2.Both the Seebeck coefficient and electrical conductivity are significantly enhanced.

3. Power factor has almost $100 \%$ enhanced after Ag doping 